\title{
Los conflictos de legalidad y los conflictos de constitucionalidad como garantía institucional de la jurisdicción constitucional
}

\author{
Catalina Salem Gesell*
}

\begin{abstract}
RESUMEN
La investigación que se presenta en este artículo busca describir cómo los denominados "conflictos de legalidad" y los "conflictos de constitucionalidad" pueden ser concebidos como garantía institucional de la jurisdicción constitucional. Estos dos conceptos han operado en la práctica como elementos de declinación o de adjudicación de competencia por parte del Tribunal Constitucional de Chile, particularmente cuando conoce de requerimientos de inaplicabilidad por inconstitucionalidad, $y$, por lo mismo, se erigen como mecanismos de deferencia entre la jurisdicción constitucional y la jurisdicción ordinaria.
\end{abstract}

Conflictos de legalidad - conflictos de constitucionalidad - tribunal constitucional

\section{Legal conflicts and constitutional conflicts as institutional guarantee of the constitutional jurisdiction}

\begin{abstract}
The research presented in this article describes how the so called "legal conflicts" and "constitutional conflicts" could be conceived as institutional guarantee of the constitutional jurisdiction. These concepts have operated in praxis as elements of declination or adjudication of jurisdiction to the Chile's Constitutional Tribunal, especially when hearing a non application decision, and, for instance, they emerged as deferential mechanisms between constitutional jurisdiction and ordinary jurisdiction.
\end{abstract}

Legal conflicts - constitutional conflicts - constitutional tribunal

\footnotetext{
* Licenciada en Derecho, Pontificia Universidad Católica de Chile. Magíster en Derecho LLM Mención Derecho Constitucional, Pontificia Universidad Católica de Chile. Profesora de Derecho Constitucional, Pontificia Universidad Católica de Chile. Correo electrónico: cesalem@uc.cl

Artículo recibido el 30 de agosto de 2016 y aceptado para su publicación en este número el 23 de julio de 2018.
} 


\section{INTRODUCCIÓN}

A diez años de la reforma que entregó al Tribunal Constitucional el control concreto de constitucionalidad de la ley, ha sido un desafío permanente en la jurisprudencia de dicho órgano tratar de definir su propia competencia. Así, al conocer de una acción de inaplicabilidad por inconstitucionalidad, el juez constitucional se encuentra en el permanente desafío de fijar el asunto que debe resolver, sin invadir las atribuciones del juez ordinario.

La tensión entre jurisdicción ordinaria y jurisdicción constitucional en sede de inaplicabilidad ha sido sistemáticamente resuelta mediante la categorización de dos tipos de conflictos jurídicos: los conflictos de legalidad, cuyo conocimiento y fallo corresponde a los tribunales del fondo; y los conflictos de constitucionalidad, cuya competencia corresponde al Tribunal Constitucional (en adelante también "el Tribunal”). La definición sobre si un determinado conflicto jurídico es de naturaleza constitucional o de mera legalidad, es una decisión autárquica que realiza el propio Tribunal.

A pesar que el Tribunal siempre ha distinguido estas dos categorías de conflictos jurídicos para atribuirse o declinar del ejercicio de su jurisdicción ${ }^{1}$, hemos notado que una conceptualización teórica de los mismos no ha encontrado un desarrollo completo en nuestra doctrina nacional ${ }^{2}$. Esto, por supuesto, influye en que las decisiones del Tribunal acerca de su propia competencia sean -a veces- un tanto veleidosas, pues sin una dogmática definida que se articule entre doctrina y jurisprudencia, los criterios varían de sentencia en sentencia ${ }^{3}$. Junto con lo anterior, la falta de dogmática respecto de esta materia ha llevado al propio Tribunal a limitar su análisis competencial a un mero ejercicio de agrupación de las alegaciones de las partes bajo los párrafos "conflicto de constitucionalidad" y "cuestiones sobre las que este Tribunal no emitirá pronunciamiento”, que han poblado prolíferamente las sentencias del último tiempo. No obstante,

\footnotetext{
${ }^{1}$ Solo a modo ejemplar, mencionamos la STC rol N 2437-13 que, en su considerando 5ㅇ, reconoció como uno de los criterios interpretativos de la sentencia "la delimitación adecuada entre los conflictos de constitucionalidad y las cuestiones de legalidad”. En el mismo sentido STC rol $N^{\circ} 2671$, cc. $3^{\circ}$ a $5^{\circ}$, STC rol N $\mathrm{N}^{\mathrm{O}} 2957$, c. $6^{\circ}$, entre otras.

${ }^{2}$ El único artículo de doctrina, entre nosotros, que aborda parcialmente esta materia, es el de MARTíNEZ, J. I., "La deferencia del Tribunal Constitucional respecto del juez de la gestión pendiente en la cuestión de inaplicabilidad”, en Estudios Constitucionales, Vol. 13, 2015, pp. 237-270.

${ }^{3}$ Como la presente investigación forma parte de una estudio más amplio que se realizó de la materia bajo análisis, solo mencionaremos en esta oportunidad que, de un estudio sistemático de la jurisprudencia del fondo del Tribunal Constitucional en que se aplicaron las categorías de conflicto de legalidad y conflicto de constitucionalidad, en varias oportunidades se identificaron inconsistencias en la aplicación de estos criterios de adjudicación de competencia. Por ejemplo, el más común -y más usualmente conocido por la doctrina especializada- es el criterio de la "interpretación conforme" (conflicto de constitucionalidad) versus el criterio que afirma que la interpretación de la ley es una materia que corresponde conocer al juez del fondo (conflicto de legalidad). Cfr. STC roles $\mathrm{N}^{\circ} 2225$, c. $9^{\circ}, \mathrm{N}^{\circ} 1314$ c. $52^{\circ}, \mathrm{N}^{\circ} 1351$ c. $40^{\circ}$ y $\mathrm{N}^{\circ} 1380$ c. $13^{\circ}$, entre otras.
} 
en su jurisprudencia, solo se han hecho contados esfuerzos por definir cuándo se está en presencia de un conflicto de legalidad y cuándo ante un conflicto de constitucionalidad ${ }^{4}$.

La separación entre un conflicto de legalidad y un conflicto de constitucionalidad resulta necesaria para asegurar el principio de separación de funciones ${ }^{5}$ y el principio de supremacía constitucional ${ }^{6}$-consagrados en los artículos $7^{\circ}$ y $6^{\circ}$ de la Constitución, respectivamente-, y en esa línea opera como una garantía institucional de la jurisdicción constitucional y de la jurisdicción ordinaria, esto es, como garantía de la competencia de decisión que una y otra tiene. Por eso, en la presente investigación, nos proponemos describir algunas bases teóricas que contribuyan a comprender y a enriquecer los esfuerzos que ha venido realizando el Tribunal Constitucional en una actitud deferente hacia la justicia ordinaria.

Con el fin de lograr nuestro objetivo, argumentaremos que (1) la jurisdicción constitucional y la jurisdicción ordinaria ejercen competencias distintas; (2) que esa distinción es necesaria en nuestro modelo de control concentrado de constitucionalidad de la ley; (3) que la competencia que le corresponde ejercer a la jurisdicción constitucional está sujeta a límites institucionales y funcionales; y finalmente, (4) que la correcta interpretación de los límites institucionales y funcionales de la justicia constitucional, definen los conflictos de legalidad y los conflictos de constitucionalidad, asegurando la garantía institucional de la justicia constitucional.

\section{JURISDICCIÓN CONSTITUCIONAL Y JURISDICCIÓN ORDINARIA}

Tras la consolidación histórica del Estado constitucional de Derecho, el término “jurisdicción constitucional” alude específicamente, según Zúñiga, al "sistema de

\footnotetext{
${ }^{4} \mathrm{Ha}$ afirmado que "el Tribunal Constitucional identifica una faz activa del conflicto de constitucionalidad sometido a su conocimiento y define una faz abstencionista respecto del conflicto de legalidad que resulta ajeno a nuestras competencias". STC rol $\mathrm{N}^{\circ} 2437$, c. $7^{\circ}$. Un esfuerzo mayor por definir estos conflictos se encuentra en el voto por acoger de la STC rol No 2363 , c. $4^{\circ}$, pero no pasa más allá de una mera reflexión acerca del problema que implica separar la dimensión legal y la dimensión constitucional en un determinado conflicto que debe conocer el Tribunal.

${ }^{5}$ Así lo ha reconocido el propio Tribunal cuando identifica un conflicto de legalidad. Este "debe ser resuelto por los jueces que conocen de la causa en que incide el requerimiento, los que han de determinar la forma de decidir la controversia sometida a su decisión, competencia que este Tribunal está obligado a respetar en virtud de lo dispuesto en el inciso segundo del artículo $7^{\circ}$ de la Constitución y en conformidad con el principio de deferencia razonada hacia los poderes del Estado" (Rol $N^{\circ} 1678-10$, considerando $8^{\circ}$. En el mismo sentido STC rol N ${ }^{\circ} 1129-08$, considerando $6^{\circ}$ ).

${ }^{6}$ Concordamos con Pablo Marshall que resulta lógico "entender a la supremacía constitucional como un principio que no solamente impone el contenido material de la Constitución como requisito de la actuación de los órganos del Estado, sino que también determina las competencias dentro de las que cada órgano actúa válidamente. Ambos son dos vertientes del principio de supremacía constitucional, en la medida que las reglas de distribución de competencias también tienen rango constitucional y son prerrequisitos de la actuación de cualquier órgano". Marshall, P., "El efecto horizontal de los derechos y la competencia del juez para aplicar la Constitución”, en Estudios Constitucionales, Año 8, No 1, 2010, pp. 71-72.
} 
garantías procesales o jurisdiccionales de guarda de la supremacía de la Constitución”" En cambio, la "jurisdicción ordinaria” signaría el sistema de garantías procesales o jurisdiccionales confiadas tradicionalmente al Poder Judicial y a los órganos jurisdiccionales especializados que colaboran con él en la administración de justicia.

Ambas jurisdicciones están íntimamente ligadas mediante el ejercicio de la acción de inaplicabilidad por inconstitucionalidad y a cada una le corresponde un ejercicio jurisdiccional distinto según su competencia: mientras el Tribunal Constitucional controla la constitucionalidad de la aplicación al caso concreto de un precepto legal, al juez del fondo le corresponde la aplicación del mismo precepto según las reglas ordinarias de hermenéutica legal. Entre ambas jurisdicciones se traza un límite que dibuja su competencia, es decir, la cuota de jurisdicción que corresponde ejercer a cada una.

En sede de inaplicabilidad por inconstitucionalidad, la jurisdicción ordinaria refiere a todos aquellos jueces o tribunales, ordinarios o especiales, ante los que existe una "gestión judicial pendiente" en donde un precepto legal puede resultar decisivo en la resolución del asunto, pero que las partes o el juez estiman que su aplicabilidad al caso concreto podría ser contraria a la Constitución. Así se sigue de las disposiciones contenidas en el Art. 93 inciso primero, $\mathrm{N}^{\circ} 6^{\circ}$, e inciso undécimo, ambos de la Constitución Política, y de los Arts. 79, 80, 81 y $84 \mathrm{~N}^{\circ} 3$, todos de la ley orgánica constitucional del Tribunal Constitucional (en adelante también LOTC).

Si la jurisdicción ordinaria tiene por objeto directo - en general- la adjudicación de posturas jurídicas a alguna de las partes del proceso, tal objeto muta considerablemente tratándose de la jurisdicción constitucional. En efecto, en esta última, el objeto de la jurisdicción lo constituye el control directo al legislador que se erige como variable independiente a la pretensión que pueda tener el actor o su contradictor en el proceso constitucional. La sentencia -como acto jurisdiccional- no tendrá como objeto adjudicar un derecho a alguna de las partes, sino que verificar el cumplimiento del principio de supremacía constitucional en el proceso de aplicación concreta de una determinada disposición legal. Así, en palabras de Hesse, "la jurisdicción constitucional sirve exclusivamente a la preservación de la Constitución” 8 y, según Zúñiga, su naturaleza jurídica y orgánica se corresponde con competencias ajenas "a decisiones sobre conflictos de intereses particulares o a casos concretos con contradictorio propios de la jurisdicción ordinaria" 9 .

${ }^{7}$ ZÚÑ̃iga, F., "La acción de inaplicabilidad por inconstitucionalidad en Chile”, en BAZÁN, V. (coord.), Derecho Procesal Constitucional Americano y Europeo Tomo II, Abeledo Perrot, Argentina, 2010, p. 1055.

${ }^{8}$ Hesse, K., "La función jurisprudencial y el Tribunal Constitucional en la Ley Fundamental de Bonn", en Brage, J. (trad.), Estudios sobre la jurisdicción constitucional (Con especial referencia al Tribunal Constitucional alemán), Editorial Porrúa, México, 2011, p. 71.

9 ZúÑIGA, F., "Acción de inaplicabilidad por inconstitucionalidad: requerimiento de jueces, entre legalidad y constitucionalidad”, en Revista de Derecho Público, N 72, 2010, p. 297. 


\section{LA NECESARIA DISTINCIÓN ENTRE JURISDICCIÓN ORDINARIA Y JURISDICCIÓN CONSTITUCIONAL}

Mucho se ha escrito acerca del fundamento de la necesidad de una jurisdicción especializada y distinta a la jurisdicción ordinaria que procure la garantía de la Constitución. En general, se señala que la desvinculación de la jurisdicción constitucional de la ordinaria, refleja una concepción en donde la labor de control de constitucionalidad que se encomienda a los tribunales constitucionales resulta incompatible con la configuración del Poder Judicial vinculado al principio de legalidad concreto ${ }^{10}$, es decir, vinculado a la obligación de aplicar e interpretar la ley para los casos concretos ${ }^{11}$. Asimismo, el principio de legalidad vincula a los jueces -en último término- con el principio democrático, en la medida que la ley -en su acepción formal- es expresión de la voluntad de los órganos colegisladores -Congreso Nacional y Presidente de la República-, quienes resumen la representación política de la ciudadanía ${ }^{12}$.

Tanto las leyes como sus criterios de interpretación tienen como parámetro de validez la Constitución, norma superior del ordenamiento jurídico ${ }^{13}$. Pues bien, las normas constitucionales están llenas de elementos valorativos que requieren de un importante ejercicio de hermenéutica, con principios y reglas propias que difieren de aquellos que utilizan los jueces ordinarios.

La garantía de la Constitución en el llamado sistema "europeo" o "kelseneano" de justicia constitucional, supone entonces la prohibición al juez ordinario de asumir la labor de dotar de un contenido concreto a los principios y valores que se desprenden de las normas constitucionales al momento de enjuiciar la ley. Las razones de tal prohibición son varias y hasta el momento solo hemos anotado una de ellas: una jurisdicción especializada contribuye al ejercicio de un quehacer hermenéutico que se rige por principios propios del derecho constitucional y totalmente ajenos a los principios tradicionales de interpretación de la ley ${ }^{14}$. Además, la existencia de una jurisdicción constitucional especializada permite dar cohesión al ordenamiento jurídico basado en el principio de supremacía constitucional ${ }^{15}$. Desde una perspectiva más de fondo, los tribunales

${ }^{10}$ García, M., El control de constitucionalidad de las leyes. Recurso y cuestión de inconstitucionalidad, Jurista Editores, Lima, 2005, p. 37.

${ }^{11}$ Bulnes, L., "Efectos de las sentencias de la jurisdicción constitucional en la judicatura ordinaria", en Estudios Constitucionales 3/1, 2005, p. 56.

12 Zúñ̃ga, F., “Acción de inaplicabilidad por inconstitucionalidad: requerimiento de jueces entre legalidad y constitucionalidad”, en Revista de Derecho Público, N 72, 2010, p. 297.

${ }^{13}$ Afirmación que se deriva del principio de supremacía constitucional consagrado en el artículo $6^{\circ}$, inciso primero, de nuestra Carta Fundamental. En doctrina, ver también Brewer-Carías, A., La justicia constitucional: procesos y procedimientos constitucionales, Editorial Porrúa, México, 2007, p. 3.

${ }^{14}$ Morales, M., "Las relaciones entre Poder Judicial y Tribunal Constitucional a propósito del control represivo de inconstitucionalidad de preceptos legales en Ecuador y los efectos de las sentencias”, en Estudios Constitucionales, Año $3 \mathrm{~N}^{\circ} 1$, 2005, p. 184.

15 Reséndiz, C., "Relación entre la Jurisdicción Constitucional y la Jurisdicción Ordinaria", en Ferrer, E. (edit.), Décimo aniversario de la Reestructuración de la Suprema Corte de Justicia de la Nación, Suprema 
constitucionales tienen una naturaleza jurídico-política-que es de su esencia-y que no es deseable que se extienda -en los países que siguen el modelo austriaco-a la estructura del Poder Judicial, tradicionalmente ajena a las controversias jurídico-políticas.

Que las distintas constituciones -y nuestra Constitución- hayan optado por un sistema de jurisdicción concentrada y especializada no corresponde, entonces, al mero azar. Detrás de este sistema existen metaprincipios que justifican la desvinculación de ciertos órganos de la estructura clásica del Poder Judicial. La garantía de estos principios se hace real y efectiva mediante la atribución a ciertos órganos de una competencia específica y exclusiva -en nuestro caso, al Tribunal Constitucional- para llevar a cabo la especial y delicada labor de concretización de los principios y valores de la Constitución.

Esto ha quedado muy patente en la voluntad de nuestro constituyente, quien en el 2005 trasladó la sede del requerimiento de inaplicabilidad por inconstitucionalidad desde la Corte Suprema al Tribunal Constitucional. Asimismo, entregó no solo a las partes de un proceso judicial la legitimación activa para accionar en contra de un precepto legal, sino que también al juez de la causa ${ }^{16}$. Esta decisión política puede leerse desde dos puntos de vista, ambas caras de una misma moneda: el primero, que nuestra Constitución sigue vinculando al juez ordinario al principio de legalidad estricta (a la ley y a las normas dictadas conforme a ella); y el segundo, que la inaplicabilidad por inconstitucionalidad se erige como un privilegio jurisdiccional de la ley ${ }^{17}$. En otras palabras, no le corresponde al juez ordinario evaluar la constitucionalidad de la ley. $\mathrm{O}$ aplica la ley o acude al Tribunal Constitucional para que la inaplique, es decir, para que este último lo desvincule de su perentoria obligación de aplicarla.

Así el constituyente ha dotado de una importante protección al acto más propio y esencial del legislador -la ley-, entregándole exclusivamente al Tribunal Constitucional su control jurisdiccional.

\section{Problemas derivados de la existencia de ambos tipos de jurisdicciones}

Tempranamente, Francisco Rubio Llorente señalaba, en 1982, que la idea de la Constitución como norma suprema del ordenamiento jurídico implica un cambio profundo

Corte de Justicia de la Nación, México, 2005, p. 203 y también Morales: "Las relaciones entre Poder Judicial y Tribunal Constitucional a propósito del control represivo de inconstitucionalidad de preceptos legales en Ecuador y los efectos de las sentencias", op. cit., p. 184.

${ }^{16}$ Art. 93 inciso onceavo de la Constitución Política; también Art. 79 inciso primero de la LOTC.

${ }^{17}$ En efecto, Brage sostiene que "la finalidad esencial del control normativo concreto de la constitucionalidad, a diferencia del control abstracto, no es la de actuar como 'Guardián de la Constitución', sino la de proteger al legislador parlamentario frente al juez, impidiendo que cualquier juez pueda dejar de aplicar una ley parlamentaria en atención a su propio criterio sobre la conformidad de dicha ley con la Constitución, con la inseguridad jurídica que llevaría ese reparto difuso de la facultad de declarar inconstitucionales las leyes". Brage, J., "Estudio introductorio”, en Brage. J. (trad.), Estudios sobre la jurisdicción constitucional (Con especial referencia al Tribunal Constitucional alemán), Editorial Porrúa, México, 2011, p. 14. 
de su concepción, acompañada por una honda modificación de la organización judicial, a cuya estructura tradicional se viene a superponer un Tribunal Constitucional. ${ }^{18}$ Esta reflexión no es para nada ajena a la realidad chilena. Aún más, en nuestro caso, la situación ha sido de una complejidad mayor si consideramos que la atribución del Tribunal Constitucional para inaplicar un precepto legal, no tuvo su origen en la génesis de este órgano.

En efecto, con la reforma constitucional introducida por la Ley $\mathrm{N}^{\circ} 20.050$ el 2005 , el control represivo de constitucionalidad -que había sido una atribución de la Corte Suprema desde 1970- pasó a formar parte de las nuevas atribuciones del Tribunal Constitucional mediante la instauración de una remozada acción de inaplicabilidad, con características distintas a aquella que la precedió ${ }^{19}$. Desde entonces, el acoplamiento de la nueva organización y atribuciones de la magistratura constitucional introducido por dicha reforma, ha tenido un gran impacto en la asimilación y coordinación de sus competencias con los órganos que ejercen la jurisdicción ordinaria. Respecto de esta idea, nos recuerda Núñez que con la reforma constitucional comienza un proceso de asimilación de los poderes de control jurisdiccional del Tribunal Constitucional, que supone el reconocimiento y aceptación de un poder nuevo y ajeno para la tradicional organización judicial chilena ${ }^{20}$.

Los problemas que supone la desvinculación de los órganos judiciales frente al control propiamente constitucional tienen una incidencia gravitante en el cuestionamiento de fondo del sistema concentrado de justicia constitucional. En particular, la acción de inaplicabilidad presenta dos problemas que, si bien no abordaremos en esta oportunidad, sí están siendo analizados por nuestra doctrina nacional más reciente. El primer problema consiste en determinar cuáles son los efectos de las sentencias del Tribunal Constitucional sobre la jurisdicción ordinaria ${ }^{21}$, pues han existido ciertas discordancias entre lo ordenado por el Tribunal Constitucional y lo finalmente resuelto por los jueces del fondo ${ }^{22}$. Un segundo problema del diseño institucional de la justicia constitucional consiste en la falta de control o supervigilancia de los jueces del fondo que ejercen control difuso de

${ }^{18}$ Rubio Llorente, F., "Sobre la relación entre Tribunal Constitucional y Poder Judicial en el ejercicio de la jurisdicción constitucional”, en Revista Española de Derecho Constitucional, Año 2, 1982. N 4, pp. 44-45.

${ }^{19}$ Ver Navarro, E., “Acción de inaplicabilidad por inconstitucionalidad. Notas sobre su evolución histórica en Chile”, en Actualidad Jurídica, v. XI N²2, 2010, pp. 21-54.

${ }^{20}$ NúÑEZ, M., "Se acata pero no se cumple. Los efectos de la inaplicabilidad en el caso por no pago del bono por desempeño institucional: Gómez Montoya con Corporación Administrativa del Poder Judicial”, en Fermandois, A. (edit.), Sentencias Destacadas 2011, Instituto Libertad y Desarrollo, 2011, pp. 155-156.

${ }^{21}$ Gómez Bernales ha sido uno de los autores que se ha ocupado más recientemente de hacer un estudio sistemático del problema enunciado. Gómez, G., Las sentencias del Tribunal Constitucional y sus efectos sobre la jurisdicción común, Ediciones Universidad Diego Portales, Santiago, 2013.

${ }^{22}$ El caso más emblemático y abundantemente comentado es Gómez Montoya con Corporación Administrativa del Poder Judicial, Zonal V Región, Rol No 4518-2011, Corte Suprema, sentencia del 30 de noviembre de 2011. 
constitucionalidad de la ley ${ }^{23}$. Tanto la primera como la segunda cuestión literalmente inutilizan el ejercicio jurisdiccional atribuido al Tribunal Constitucional.

Pero hay un tercer problema que sí abordaremos, sin agotar en todo caso la materia. Ese problema se produce en la delimitación de competencias que se le han atribuido al órgano que ejerce jurisdicción ordinaria y aquel que ejerce la jurisdicción constitucional en sede de inaplicabilidad, y que incide necesariamente en cómo ambos se coordinan en el ejercicio de sus respectivas competencias y, en definitiva, cómo el Tribunal Constitucional respeta la garantía institucional del juez del fondo, así como también la propia.

Si bien nuestra Constitución consagra la justicia ordinaria y la justicia constitucional como jurisdicciones independientes y autónomas, resulta más o menos claro que ambas deben complementarse ${ }^{24}$ y coordinarse ${ }^{25}$, pues se parte del supuesto que el constituyente quiso -y así consagró- que ambas ejercieran atribuciones exclusivas y distintas, sin superposición de competencias ${ }^{26}$. Para sostener esta afirmación es necesario demostrar que entre ambas existe un límite competencial y que ese límite se encuentra consagrado, primero, a nivel normativo; y, segundo, que ese límite normativo tiene un correlato jurisprudencial, es decir, que los órganos aplicadores del Derecho tienen una comprensión institucional de lo que su competencia es y hasta dónde se extiende.

Arribar a alguna conclusión en esta materia no es un camino fácil. En efecto, aparte del esquema abstracto de un tipo específico de sistema de justicia constitucional adoptado por el constituyente como decisión política soberana, es posible preguntarse cómo tal sistema se encuentra consagrado a nivel normativo y qué tan perfecta es la técnica normativa utilizada por el constituyente -o por el legislador orgánico- para institucionalizarlo en el derecho positivo. De esa perfección técnica dependerá la comprensión que el Tribunal Constitucional -y quienes se relacionan con él en sede de inaplicabilidadtenga sobre su propia competencia, comprensión que es inducida mediante las reglas de hermenéutica constitucional. ${ }^{27}$.

${ }^{23}$ En este sentido, existe un valioso y reciente trabajo de Manuel Núñez que ha tratado de discernir los conceptos de "inaplicación” y "desaplicación” de las leyes en el ejercicio de la jurisdicción y control concreto de constitucionalidad, como atribuciones distintas y concurrentes del Tribunal Constitucional y los jueces del fondo. NúÑEZ, M., "Desaplicación e inaplicación jurisdiccional de las leyes en Chile: Ejercicio de la jurisdicción y control concreto de constitucionalidad”, en Revista de Derecho de la Universidad Católica del Norte, Año 19, $\mathrm{N}^{\circ}$ 2, 2012.

${ }^{24}$ Bulnes, L., "Efectos de las sentencias de la jurisdicción constitucional en la judicatura ordinaria" op. cit., p. 56.

${ }^{25}$ CEA, J.L., "El proyecto de reforma constitucional sobre los efectos de las sentencias del Tribunal Constitucional sobre la justicia ordinaria", en Estudios Constitucionales 3/1, 2005, p. 69.

${ }^{26}$ El objeto de la coordinación y complementación que debe existir entre la jurisdicción ordinaria y la jurisdicción constitucional, está dado por el fin de velar por el cumplimiento del principio de legalidad y el principio de supremacía constitucional, al mismo tiempo.

${ }^{27}$ Alfonso Herrera parte de la premisa que toda Constitución no siempre es perfectamente coherente en su ensamblaje técnico, pues puede incurrir en excesos, desequilibrios o inconsistencias estructurales, que plantean disyuntivas de sistemática institucional. Herrera, A., "El recurso de amparo en el modelo kelseniano de control de constitucionalidad de las leyes ¿un elemento atípico?”, en BAZÁN, V., (coord.), Derecho Procesal Constitucional Americano y Europeo Tomo II, Abeledo Perrot, Argentina, 2010, p. 954. 
En consecuencia, es factible preguntarnos si es correcto el ensamblaje técnico que realiza nuestra Constitución respecto de la jurisdicción constitucional y la jurisdicción ordinaria. Asimismo, si nuestro constituyente ha definido con exactitud las competencias del Tribunal Constitucional y si la ley orgánica constitucional del Tribunal Constitucional plantea alguna disyuntiva de sistemática constitucional.

Una vez contestadas las interrogantes anotadas, resultará necesario comprobar la existencia de un correlato jurisprudencial respecto de ese ensamblaje técnico, lo que implica un estudio caso a caso de las decisiones del Tribunal Constitucional. Es allí, en cada una de sus sentencias, donde el Tribunal reflexiona -mediante la hermenéutica constitucional-acerca de las competencias que le han sido confiadas y cómo ellas operan en el caso concreto de que conoce.

\section{LOS LÍMITES DE LA JURISDICCIÓN CONSTITUCIONAL}

Un primer paso para determinar la competencia que corresponde a un cierto órgano del Estado, consiste en conocer cuáles son sus límites normativos; y, en segundo lugar, cómo esos límites normativos son comprendidos por el propio órgano en el ejercicio de sus atribuciones.

Como ya hemos tenido oportunidad de explicar, la acción de inaplicabilidad por inconstitucionalidad tiene su sede natural en el Tribunal Constitucional. De este modo, en ejercicio de tal acción, cualquier trazado de frontera entre jurisdicción ordinaria y jurisdicción constitucional debe partir del análisis competencial efectuado en esta sede. Además, como veremos, es el Tribunal Constitucional el intérprete primero y último de sus propios límites, y esos límites funcionan -al mismo tiempo-como reconocimiento o desconocimiento de las propias competencias del juez del fondo, y por tanto se erige como garantía institucional del mismo.

Konrad Hesse, quien fuera profesor y exjuez del Tribunal Constitucional alemán, resumió las premisas que hemos venido analizando hasta ahora sosteniendo que la justicia constitucional está sometida a dos tipos de límites: los límites institucionales y los límites funcionales ${ }^{28-29}$.

${ }^{28}$ Hesse, K., Escritos de Derecho Constitucional, Fundación Coloquio Jurídico Europeo y Centro de Estudios Políticos y Constitucionales, Madrid, 2011, p. 178.

${ }^{29}$ Esta doctrina también es compartida por Manuel Medina Guerra y Tomás y Valiente. El primero afirma que los límites funcionales de la jurisdicción constitucional consisten en que el propio Tribunal, como supremo intérprete de la Constitución, determina de modo vinculante el sentido de los preceptos constitucionales y por ello le corresponde también delimitar sus propias funciones, acotando su jurisdicción del ámbito de actuación perteneciente a los tradicionales poderes del Estado. Tomás y Valiente, en un sentido similar, afirma que, dentro del sistema que es la Constitución, nadie puede decirle al Tribunal cuáles son sus límites, lo que no significa que no los tenga, sino que estos son los que la Constitución dicen que son, en unos términos cuyo sentido establece el propio Tribunal como intérprete supremo. Ambos citados por Colombo, J., "Los tribunales constitucionales: entre la judicialización de la política y la politización de la 
El primer límite él lo llama “institucional”, el que se deduciría fácilmente de la propia Ley Fundamental, de las reglas relativas a la competencia del Tribunal Constitucional, de las reglas procesales - principalmente de los requisitos de admisión de la demanda y de los propios legitimados para sustanciarla-, de la organización del Tribunal y de los requisitos de justiciabilidad. En su opinión, tanto los límites institucionales como los derivados de la tutela judicial permiten desarrollar parámetros normativos con los cuales dirigir la dimensión del control del Tribunal Constitucional ${ }^{30}$. Agrega que "En conjunto, conducen a una cierta garantía de la competencia de decisión de los otros poderes, esto es, a la definición de límites funcionales para la justicia constitucional" 31 .

De acuerdo con estas pautas, los límites institucionales vendrían a ser aquellas normas jurídicas que fijan las reglas de organización, competencia y justiciabilidad que regulan el ejercicio de las atribuciones encargadas al órgano. A su vez, esas mismas normas jurídico-positivas permiten desarrollar parámetros normativos que enmarcan funcionalmente el ejercicio de las atribuciones del órgano. Estos parámetros son los que Hesse reconoce como los "límites funcionales" de la justicia constitucional.

La importancia de la existencia y coincidencia de ambos tipos de límites es que, para que el Tribunal Constitucional no se extralimite en la cuota de poder que se le ha asignado, no basta simplemente que actúe dentro de su competencia o de acuerdo con sus reglas procesales, sino que, además, debe actuar de acuerdo con la función que se le ha encomendado. Así, por ejemplo, si el Tribunal interpreta ampliamente sus reglas de competencia para cautelar una vulneración al principio de supremacía constitucional, esa interpretación extensiva puede invadir la esfera de atribuciones de otro órgano. $\mathrm{O}$ viceversa, cuando el Tribunal interpreta de manera excesivamente restringida sus reglas de competencia, por ejemplo, para dar primacía al principio de deferencia al legislador, ello puede significar el sacrificio de sus límites funcionales, esto es, el sacrificio de aquellos principios normativos que guían la garantía jurisdiccional de la Constitución. Por ello, entre los límites institucionales y los límites funcionales debe existir una cierta coincidencia ${ }^{32}$, ya que solo si se cumple esa coincidencia, no hay transgresión a la competencia de decisión de otros órganos o, a su vez, no hay una autotransgresión a la propia competencia y función del Tribunal Constitucional.

Si bien Hesse centra su preocupación en la extensión o amplitud de la competencia del Tribunal Constitucional Federal alemán respecto de los demás poderes del Estado, sus reflexiones de igual modo nos sirven de orientación en los planteamientos más acotados de nuestra investigación. Ello porque, en nuestro caso, la delimitación de competencia -en un sentido institucional- impone límites funcionales no solo al Tribunal Constitucional, sino que también al juez ordinario respecto de las atribuciones del primero.

justicia constitucional", en La Ley Fundamental alemana y la Constitución Política chilena. Estudio constitucional comparado, Editorial Jurídica de Chile, Santiago, 2007, pp. 47-48.

${ }^{30}$ Hesse, K., Escritos de Derecho Constitucional, op. cit., p. 187.

${ }^{31}$ Hesse, K., Escritos de Derecho Constitucional, op. cit., p. 187.

${ }^{32}$ Hesse, K., Escritos de Derecho Constitucional, op. cit., p. 180. 
Con lo dicho podemos afirmar que la delimitación institucional y funcional del Tribunal resulta necesaria, pues funciona como una garantía de no vulneración de la competencia del juez del fondo y de la propia, es decir, como una garantía institucional y, por tanto, del principio de separación de funciones y de supremacía constitucional.

\section{Los limites institucionales de la Justicia Constitucional}

Según Hesse, como ya tuvimos oportunidad de explicar, los límites institucionales de la justicia constitucional son los límites jurídico-constitucionales, es decir, aquellos que se deducen fácilmente de la Ley Fundamental y, en nuestro caso, además, de la ley orgánica constitucional del Tribunal Constitucional, por expresa disposición del inciso final del artículo 92 de la Carta Política. Asimismo, como mencionamos, el profesor alemán estima que el límite institucional resulta igualmente claro producto de los requisitos de justiciabilidad. Agrega que "estos límites conducen a relevantes constricciones prácticas de competencias y posibilidades de decisión del Tribunal Constitucional [...], que en ningún caso, pese a su amplitud, son ilimitadas" 33 .

\section{i. La organización del Tribunal}

Siguiendo el mismo esquema propuesto por Hesse, un primer límite institucional de la justicia constitucional estaría dado por la forma en que se organiza el Tribunal Constitucional, regulada en el artículo 92 de la Carta Fundamental, como también en el Título I del Capítulo I de la LOTC. La organización del Tribunal no solo concretiza el derecho al juez natural, sino que también constituye un límite institucional de la jurisdicción constitucional, pues convoca a los jueces que conforman el órgano colegiado. Solo los titulares de este órgano, regularmente investidos, pueden resolver las cuestiones que se le han encomendado en virtud de su competencia y conforme al procedimiento legal establecido.

\section{ii. Las reglas relativas a la competencia}

Un segundo límite institucional de la Justicia Constitucional está dado por las reglas de competencia del Tribunal Constitucional.

En el caso del Tribunal Constitucional chileno, las reglas de competencia se encuentran consagradas tanto en la Constitución Política como en la LOTC. Así, en lo que al requerimiento de inaplicabilidad se refiere, la Ley Fundamental dispone en su artículo $93 \mathrm{~N}^{\circ} 6^{\circ}$ que el Tribunal tiene competencia solo para declarar la inaplicabilidad de un precepto legal cuya aplicación sea contraria a la Constitución en cualquier gestión judicial pendiente, siempre que concurra a la resolución la mayoría de sus miembros en ejercicio. De esta norma de competencia, al mismo tiempo, se deduce el requisito de

\footnotetext{
${ }^{33}$ Hesse, K., Escritos de Derecho Constitucional, op. cit., p. 178.
} 
justiciabilidad que debe tener todo asunto que se promueva en sede de inaplicabilidad: Que la norma legal aplicable a la gestión judicial pendiente sea contraria a la Constitución. Esta afirmación deja fuera un sinnúmero de casos, como por ejemplo, que una determinada norma legal sea defectuosa en su formulación, o que presente una solución que podría ser sustituida por otra mejor. La labor del Tribunal no consiste en perfeccionar el ordenamiento jurídico, sino que en depurarlo, en una gestión judicial concreta, de la aplicabilidad de una norma determinada que contradice la Constitución. Lo justiciable por el Tribunal en ejercicio de su competencia es la supremacía constitucional.

iii. Las reglas procesales

El tercer límite institucional se deduciría de las reglas procesales, en especial, aquellas que se refieren a los requisitos de admisibilidad y a los órganos o personas legitimados para sustanciar el proceso de inaplicabilidad.

Prefiriendo un orden cronológico del desarrollo del proceso constitucional de inaplicabilidad, las reglas procesales que fijan la competencia del Tribunal serían las que se anotan a continuación:

\section{Los sujetos legitimados}

Por expresa disposición constitucional, los sujetos legitimados para iniciar una cuestión de inaplicabilidad son cualquiera de las partes de la gestión judicial pendiente o el juez que conoce de ella (Art. 93, inciso undécimo). La ley orgánica especifica que, en el primer caso, se trata de personas legitimadas, mientras que en el segundo, de órgano legitimado (Art. 79, inciso primero, de la LOTC). Solo estos sujetos pueden iniciar un proceso de inaplicabilidad por inconstitucionalidad; quien no se encuentre en alguna de estas dos situaciones, simplemente estará promoviendo una cuestión que no es competencia del Tribunal Constitucional.

\section{La admisión a trámite}

Mientras la Constitución se encarga de fijar la competencia del Tribunal Constitucional (Art. $93 \mathrm{~N}^{\circ} 6^{\circ}$ ) y de establecer los requisitos de procesabilidad de la acción de inaplicabilidad (Art. 93, inciso undécimo), la LOTC fija un primer trámite en el iter procesal que permite al Tribunal, por primera vez en el proceso de inaplicabilidad, imponerse de una solicitud (el requerimiento) que insta el ejercicio de su jurisdicción.

En efecto, el artículo 82 de la LOTC exige al requirente cumplir con lo dispuesto en los artículos 79 y 80 del mismo cuerpo legal, con el fin de que su requerimiento sea acogido a tramitación. De la lectura de esos requisitos podemos resumir que la admisión a trámite es un límite institucional de la justicia constitucional, pues se trata, a nuestro juicio, de una herramienta que le permite al Tribunal preparar el examen de procesabilidad -la admisibilidad-que debe realizar de manera previa a entrar al fondo del conocimiento del asunto. Un requerimiento que no cumple con los requisitos de 
admisión a trámite, simplemente no podrá vincular el ejercicio de la competencia del Tribunal, pues no ha tenido la aptitud de probar la existencia de antecedentes mínimos indiciarios de que el asunto que promueve es una materia que corresponde ser conocida y resuelta en sede de inaplicabilidad.

En efecto, si se leen con detención los requisitos de admisión a trámite, estos tienen por objeto proporcionar los antecedentes necesarios, sin estos, el Tribunal no puede decidir si la materia sometida a su conocimiento es de aquellas que la Constitución ha puesto bajo la esfera de sus atribuciones ${ }^{34}$. Reunidos todos los requisitos legales, el Tribunal se encuentra en posición para pronunciarse, conforme a derecho, respecto de la procesabilidad de la acción.

\section{La admisibilidad}

La admisibilidad es la segunda etapa del iter procesal de la inaplicabilidad y algunos de sus requisitos reiteran cuestiones que han quedado resueltas en la etapa de admisión a trámite, lo que ha llevado a muchos a sostener que esta última es una etapa artificiosa y poco práctica ${ }^{35}$. En cualquier caso, la admisibilidad constituye un examen de procesabilidad que permite al Tribunal determinar si el asunto sometido a su conocimiento se encuentra dentro de la esfera de competencia definida en el número $6^{\circ}$ del artículo 93 de la Constitución, es decir, su competencia específica.

En efecto, con este examen previo, el constituyente y el legislador orgánico han querido precaver que se active la jurisdicción constitucional acerca de un asunto que no es de su incumbencia. Por ejemplo, respecto del requisito de admisibilidad que exige que el requerimiento cuente con una fundamentación razonable, el Tribunal ha declarado que uno de sus sentidos es que "no se traben juicios de inaplicabilidad cuyo objeto resulte tan difuso o confuso que el Tribunal no pueda determinar su competencia específica" 36 .

La procesabilidad, entonces, en palabras de Peña, "alude a la idoneidad del requerimiento desde el punto de vista del cumplimiento de los requisitos que hacen procedente la acción de inaplicabilidad a la luz de lo preceptuado por la propia Constitución". Luego, los requisitos de admisibilidad son un límite institucional, pues permiten que el Tribunal fije su competencia confrontando las normas constitucionales y legales aplicables, con el caso específico en el que ha de recaer el ejercicio de su jurisdicción. Por ello agrega que la declaración de inadmisibilidad constata que "no concurren los

${ }^{34}$ Evidentemente, los requisitos de admisión a trámite tienen también otros objetivos relacionados con el derecho al debido proceso, como por ejemplo, la necesidad de indicar los domicilios de las partes y sus apoderados permiten llevar a cabo las notificaciones del proceso y, además, poner a las partes en conocimiento de un asunto jurisdiccional en que querrán hacer efectivo su derecho a defensa. Asimismo, se exige que el requerimiento tenga una cierta lógica y coherencia, sin esta las peticiones que se someten al fallo del Tribunal resultan ininteligibles.

${ }^{35}$ Cfr. PiCA, R., “Algunos nudos procesales del control de inaplicabilidad por inconstitucionalidad en la ley orgánica constitucional del Tribunal Constitucional”, en NogueIRA, H., (coord.), Reflexiones acerca del Tribunal Constitucional y sus competencias a ocho años de la reforma de 2005, Librotecnia, Santiago, 2013, p. 11.

${ }^{36}$ Artículo $4^{\circ}$ inciso segundo de la ley $N^{\circ} 19.260$, STC rol No $1260-08$, c. $7^{\circ}$. 
requisitos constitucionales y legales que permiten que el Tribunal Constitucional ejerza su competencia para decidir la inaplicabilidad solicitada" 37 .

No es el propósito de nuestra investigación hacer un estudio jurisprudencial de las sentencias de inadmisibilidad del Tribunal Constitucional, de lo que nuestra doctrina en todo caso sí se ha hecho cargo ${ }^{38}$. Pero no podemos dejar de llamar la atención en dos puntos muy relevantes a los objetivos que nos hemos propuesto desarrollar en el presente estudio.

El primer punto a resaltar es que, es en esta etapa, como dijimos, que el Tribunal interpreta sus límites institucionales conforme al caso concreto que se le ha sometido a juzgamiento y determina si tiene o no competencia para conocer de él. Vencida la etapa de admisión a trámite, la admisibilidad es el tamiz más importante y definitivo que tiene el Tribunal para decidir su competencia, pues declarada la admisibilidad, no queda más que conocer del fondo del asunto. Pero ¿qué sucede cuando este tamiz falla y el Tribunal entra a conocer un asunto que nunca estuvo dentro de la esfera de su competencia? ¿Puede resolver la procesabilidad de la acción en la etapa posterior, esto es, en la etapa de fondo? Su jurisprudencia demuestra que sí puede hacerlo, pero con una carga argumentativa mucho mayor ${ }^{39}$.

El segundo punto a destacar es que los dos últimos requisitos que contempla el artículo 84 de la LOTC -a saber, la aplicabilidad decisiva del precepto legal impugnado $\left(\mathrm{N}^{\circ} 5^{\circ}\right)$ y la exigencia de fundamento plausible del requerimiento $\left(\mathrm{N}^{\circ} 6^{\circ}\right)_{-}$, presentan el mayor desafío para la fijación de la competencia del Tribunal, pues comulgan íntimamente con la competencia del juez del fondo. Piénsese que el requisito consignado en el número $5^{\circ}$ supone que el juez constitucional se sitúe en el lugar del juez ordinario y desde esa esfera prevea la aplicabilidad o decisividad de un determinado precepto legal. Eso evidentemente supone efectuar una interpretación legal no solo del precepto, sino que también de las instituciones jurídicas que lo rodean y que tienen una consagración a nivel legal o incluso infralegal. Mientras, el último requisito -consignado en el número $6^{\circ}$ del artículo 84 de la LOTC- ha permitido al Tribunal en su jurisprudencia de inadmisibilidad establecer varios criterios, más o menos objetivos, acerca de qué ha de entenderse que el requerimiento "carezca de fundamento plausible". Uno de dichos criterios determina precisamente que carece de fundamento plausible el requerimiento que plantea un "conflicto de legalidad", esto es, un conflicto de aquellos que le corresponde conocer a los jueces del fondo y no al juez constitucional. Luego, la determinación de

37 PeÑA, M., “Admisibilidad de requerimientos de inaplicabilidad: Jurisprudencia del Tribunal Constitucional chileno”, en BAZÁN. V. (coord.), Reflexiones acerca del Tribunal Constitucional y sus competencias a ocho años de la reforma de 2005, Librotecnia, Santiago, 2010, p. 1042.

${ }^{38}$ Por ejemplo, ver Navarro, E., "Criterios del Tribunal Constitucional en materia de admisibilidad de la acción de inaplicabilidad por inconstitucionalidad de las leyes", en XXXVII Jornadas de Derecho Público, 2007, pp. 189-198.

${ }^{39}$ A modo ejemplar, se pueden citar las sentencias del Tribunal Constitucional roles $\mathrm{N}^{\circ}$ s 2321,2290 , 2278 y 2364. 
si un determinado conflicto es uno de naturaleza constitucional o legal, es una cuestión de procesabilidad y, por lo mismo, es un problema de competencia.

En cualquier caso, tanto en las sentencias de inadmisibilidad como en las sentencias de fondo, el Tribunal constitucional siempre hace una breve reflexión respecto de sus límites institucionales antes de resolver el asunto. Esto se aprecia claramente en los primeros considerandos de sus fallos cuando cita expresamente aquellas normas que le otorgan la competencia para conocer del asunto, subsumiendo las peticiones de los requirentes y las características de las gestiones judiciales pendientes a cada uno de los requisitos de procesabilidad que hemos visto. A mayor abundamiento, en ciertas sentencias el Tribunal ha diferido las disputas pertinentes a la naturaleza de un determinado conflicto sometido a su conocimiento, recurriendo, además, a los límites institucionales del Poder Judicial. Por ejemplo, ha resuelto que no le corresponde controlar la validez de las actuaciones judiciales, por ser una atribución de la jurisdicción ordinaria en virtud del artículo 76 de la Constitución, a quien corresponde la exclusividad del ejercicio de la misma, rigiendo la regla de inavocabilidad, "además de las normas legales sobre nulidad procesal y recursos de casación contenidas en el Código de Procedimiento y la regla de competencia de la extensión contenida en el Código de Procedimiento Civil” ${ }^{40}$. En términos similares, también ha declarado que la acción de inaplicabilidad no es la vía procesal idónea "para impugnar resoluciones judiciales de tribunales ordinarios o especiales con la finalidad de revocar, enmendar, revisar, casar o anular estas; ya que la guarda del imperio de la ley en el conocimiento, juzgamiento y ejecución de lo juzgado en general, y de la sustanciación en particular, de las causas civiles y criminales, corresponde exclusivamente a los tribunales creados por ley a través de las vías procesales previstas en las leyes de enjuiciamiento" 11 .

\section{Los límites funcionales de la Justicia Constitucional}

Destaca Hesse que los límites funcionales de la justicia constitucional son de sobra conocidos, pero a la vez son los menos claros. En términos abstractos, el límite funcional consiste en que el Tribunal debe actuar en el marco de las competencias que le han sido atribuidas ${ }^{42}$. Dice el autor que "Así, en el control de los otros poderes estatales no debe ir hasta el punto de ocupar las funciones que le son ajenas, esto es, no puede convertirse en legislador, sustituir al Gobierno en la dirección política o decidir las causas propias de la jurisdicción ordinaria" 43 .

Los límites funcionales del Tribunal Constitucional se corresponden con la defensa de la supremacía constitucional mediante el ejercicio de las competencias otorgadas para tal fin, pues esa es la función que se le ha encomendado. El respeto a esos límites,

\footnotetext{
${ }^{40}$ STC roles $\mathrm{N}^{\mathrm{o}} 1204$, c. $1^{\circ}$ y $\mathrm{N}^{\mathrm{o}} 1309$, c. $1^{\circ}$.

${ }^{41}$ STC roles $\mathrm{N}^{\circ} 1568$, c. $21^{\circ}$ y $\mathrm{N}^{\circ} 1576$, c. $35^{\circ}$.

${ }^{42}$ Hesse, K., Escritos de Derecho Constitucional, op. cit., p. 178.

${ }^{43}$ Hesse, K., Escritos de Derecho Constitucional, op. cit., p. 179.
} 
en conjunto con los límites institucionales del órgano, constituye una garantía al principio de separación de funciones y de supremacía constitucional, según hemos tenido oportunidad de argumentar.

Ahora bien, mientras los límites institucionales son fáciles de aprehender mediante un estudio sistemático de aquella parte del ordenamiento jurídico positivo que regula al órgano, los límites funcionales de la justicia constitucional son mucho más difíciles de asir. Esto porque los límites funcionales se van perfilando en un conjunto de premisas que formula el propio Tribunal mediante una autocomprensión de sus límites institucionales. Esa autocomprensión la hace caso a caso, desarrollando principios normativos que han de observarse en el ejercicio de las funciones que la Constitución le ha otorgado.

Como ya señaláramos, los límites institucionales son fijados por el constituyente y -en nuestro caso- también por el legislador orgánico. De este modo, estos límites resultan inmodificables por el propio Tribunal, sin que pueda "atribuirse, ni aún a pretexto de circunstancias extraordinarias, otra autoridad o derechos que los que expresamente se le hayan conferido en virtud de la Constitución o las leyes" (artículo 7, inciso segundo, de la Constitución).

No sucede lo mismo, en cambio, con los límites funcionales. Estos -reiteramos- se desprenden de los límites institucionales mediante una operación hermenéutica que tiene como resultado principios normativos que guían la dimensión del control del Tribunal Constitucional. Lo que cabe precisar a continuación es qué órgano tiene la competencia para la realización de esa operación hermenéutica; y en segundo lugar, cómo a partir de esa operación se determina la formulación concreta de la panoplia de principios normativos que concretizan los límites funcionales de la justicia constitucional.

En el caso del Tribunal Constitucional chileno, el órgano encargado de llevar a cabo el proceso interpretativo de sus límites institucionales es el propio Tribunal por disposición de la misma LOTC, que en su artículo 21 dispone que "En ningún caso se podrá promover cuestión de jurisdicción o competencia del Tribunal. Solo este, de oficio, podrá conocer y resolver su falta de jurisdicción o competencia”.

A mayor abundamiento, también debe tenerse presente que, en virtud de aquellas atribuciones que el constituyente le ha confiado al Tribunal Constitucional, este se erige como intérprete último del sistema positivo de normas constitucionales, así como se desprende del artículo 94, inciso primero, de la Carta Fundamental que prescribe "Contra las resoluciones del Tribunal Constitucional no procederá recurso alguno, sin perjuicio de que puede, el mismo Tribunal, conforme a la ley, rectificar los errores de hecho en que hubiere incurrido".

A la luz de estas dos normas, lo correcto es afirmar entonces que es el Tribunal Constitucional quien tiene la competencia para fijar sus propios límites funcionales ${ }^{44}$. Esto implica que el juez del fondo -o las partes- deberá aducir en el mismo proceso

${ }^{44}$ Acerca de este punto también hemos encontrado apoyo en la doctrina, ver Colombo, J., El debido proceso constitucional, Editorial Porrúa, México, 2007, pp. 47-48. 
constitucional cualquier alegación respecto de la competencia que tenga o no tenga el Tribunal para conocer del asunto que le ha sido sometido a su conocimiento.

Los principios normativos más comunes en la jurisprudencia del Tribunal Constitucional que funcionan como límite funcional son, entre otros, los distintos conflictos de legalidad que lo llevan a abstenerse de ejercer jurisdicción, como la resolución o determinación de cuestiones de hecho ${ }^{45}$, la calificación jurídica de los hechos ${ }^{46}$, la titularidad y reconocimiento de derechos legales ${ }^{47}$, los conflictos de aplicación e interpretación de leyes ${ }^{48}$, el control de actos administrativos ${ }^{49}$ y actuaciones judiciales ${ }^{50}$ y el amparo de derechos fundamentales ${ }^{51}$. Otros criterios identificados como adjudicadores de competencia, es decir, como conflictos de constitucionalidad, son la inconstitucionalidad sobreviniente de un precepto legal ${ }^{52}$, los conflictos que no pueden ser solucionados por una mera interpretación legal ${ }^{53}$ y los conflictos de intensidad constitucional ${ }^{54}$, aunque los dos últimos son casos anómalos como explicaremos en el acápite siguiente.

\section{LOS LÍMITES INSTITUCIONALES Y FUNCIONALES COMO GARANTÍA INSTITUCIONAL DE LA JURISDICCIÓN CONSTITUCIONAL}

Como hemos dicho, los límites funcionales de la justicia constitucional son el "desarrollo de una panoplia de principios normativos, que, en su conjunto, y unidos a los institucionales, marcan límites decisivos a la justicia constitucional" 55 . Estos límites son definidos por el propio Tribunal, como supremo intérprete de la Constitución en sede de inaplicabilidad y -por esta razón- de los límites institucionales que esta le impone.

La determinación de los límites funcionales es de la mayor relevancia para nuestra compresión de la jurisdicción constitucional, por varias razones ${ }^{56}$. Primero, porque los principios normativos que se inducen de la interpretación concreta de los límites institucionales son vinculantes tanto para el propio Tribunal como para los demás operadores jurídicos que acuden o se relacionan con esa sede. Y son vinculantes porque resultan del mismo derecho constitucional, tanto en su sentido formal como material;

${ }^{45}$ Cfr. STC roles $\mathrm{N}^{\circ} 1284$, c. $3^{\circ}, \mathrm{N}^{\circ} 1432$, c. $40^{\circ}, \mathrm{N}^{\circ} 1413$, c. $4^{\circ} \mathrm{N}^{\circ} 20.66$, c. $3^{\circ}$, entre otras.

${ }^{46}$ Cfr. STC roles $\mathrm{N}^{\circ} 2437$, c. $11^{\circ}, \mathrm{N}^{\circ} 2314$, c. $5^{\circ}$ y $\mathrm{N}^{\circ} 2344$, c. $12^{\circ}$, entre otras.

${ }^{47}$ Cfr. STC rol $\mathrm{N}^{\circ} 804$, c. $12^{\circ}, \mathrm{N}^{\circ} 2077$, c. $29^{\circ}$ y $\mathrm{N}^{\circ} 2437$, c. $10^{\circ}$, entre otras.

${ }^{48}$ Cfr. STC roles $\mathrm{N}^{\circ} 1463$, c. $5^{\circ}, \mathrm{N}^{\circ} 1872$, c. $27^{\circ}, \mathrm{N}^{\circ} 1182$, c. $6^{\circ}, \mathrm{N}^{\circ} 1201$, c. $6^{\circ}, \mathrm{N}^{\circ} 1295$, c. $33^{\circ}$, $\mathrm{N}^{\circ} 1485$, c. $8^{\circ}, 1732$, c. $3^{\circ}, 1669$, c. $4^{\circ}$, entre otras.

${ }^{49}$ Cfr. STC roles $\mathrm{N}^{\circ} 2066$, c. $3^{\circ}, \mathrm{N}^{\circ} 2346$, c. $11^{\circ}$ y $\mathrm{N}^{\mathrm{o}} 2024$, c. $12^{\circ}$, entre otras.

${ }^{50}$ Cfr. STC roles $\mathrm{N}^{\mathrm{o}} 1295$, c. $33^{\circ}, \mathrm{N}^{\mathrm{o}} 1298$, c. $5^{\circ}, \mathrm{N}^{\mathrm{o}} 2014$, c. $6^{\circ}, \mathrm{N}^{\mathrm{o}} 1576$, c. $35^{\circ}$ y $\mathrm{N}^{\mathrm{o}} 2337$, c. $12^{\circ}$, entre otras.

${ }^{51}$ Cfr. STC roles $\mathrm{N}^{\circ} 1266$, c. $6^{\circ}, \mathrm{N}^{\circ} 1041$, c. $8^{\circ}$ y $\mathrm{N}^{\circ} 2364$, c. $10^{\circ}$, entre otras.

52 Cfr. STC roles $\mathrm{N}^{\circ} 1448$, c. $55^{\circ}, \mathrm{N}^{\circ} 991$, c. $5^{\circ}$ y $\mathrm{N}^{\circ} 1230$, c. $11^{\circ}$, entre otras.

${ }^{53}$ Cfr. STC roles $\mathrm{N}^{\circ} 2246$, cc. $6^{\circ}$ y $7^{\circ}$ y $\mathrm{N}^{\mathrm{o}} 2379$, cc. $6^{\circ}$ y $7^{\circ}$.

${ }^{54}$ Cfr. STC roles $\mathrm{N}^{\circ} 2437$, c. $7^{\circ}$ y $\mathrm{N}^{\circ} 2363$, c. $4^{\circ}$, voto por acoger.

55 Hesse, K., Escritos de Derecho Constitucional, op. cit., p. 180.

${ }^{56}$ Expuestas resumidamente por Hesse, K., Escritos de Derecho Constitucional, op. cit., p. 181. 
allí es donde encuentran su fundamentación y desarrollo. En segundo lugar, porque esos principios determinan y hacen previsible el parámetro que ha de orientar las competencias de control del Tribunal Constitucional. Esto último, sin duda, refuerza el principio de certeza jurídica que ha de guiar la actuación de los órganos del Estado, lo que se logra en mayor medida cuando estos parámetros se encuentran consagrados en líneas jurisprudenciales uniformes y constantes en el tiempo, aun cuando en nuestro sistema no exista el precedente en sentido estricto.

En otras palabras, la identificación de los principios normativos que constituyen los parámetros de delimitación de competencias del Tribunal Constitucional constituye una herramienta útil y relevante para decidir futuros conflictos de jurisdicción o competencia que se presenten en dicha sede. Y, en específico, para poder discernir cuándo se está en presencia de un conflicto de legalidad y cuándo ante uno de constitucionalidad. Pero, también, una vez identificados esos principios, permiten evaluar su aplicación y si esta se condice o no con los límites institucionales de la justicia constitucional. Si no hay una correspondencia entre ambos límites -institucionales y funcionales-, la interpretación forzada llevará inexorablemente a un desbordamiento competencial contrario al Estado de Derecho. Es lo que sucede, por ejemplo, con el principio normativo que define aquellos conflictos que no pueden ser solucionados por una mera interpretación legal (STC roles $\mathrm{N}^{\circ} 2246$ y $\mathrm{N}^{\circ}$ y 2379) y los conflictos de intensidad constitucional (STC roles $\mathrm{N}^{\circ} 2437$ y $\mathrm{N}^{\mathrm{o}} 2363$, en el voto por acoger). En el primero, el Tribunal interpretó que, en virtud del Art. $93 \mathrm{~N}^{\circ} 6^{\circ}$ de la Constitución, bastaba que un precepto legal tuviera una sola interpretación contraria a la Constitución para que fuera suficiente declarar su inaplicabilidad, reconociendo que si bien en otras oportunidades su jurisprudencia había preferido aquella interpretación conforme a la Constitución, en esta ocasión, para dar "mayor eficacia" a su decisión, optaba por la inaplicabilidad ${ }^{57}$. ¿Qué límite institucional del Tribunal Constitucional le entrega una facultad discrecional para controlar interpretaciones judiciales cuando deba darle "mayor eficacia” a una determinada decisión? ¿Debemos entender que se requiere dar eficacia cuando el juez del fondo es contumaz en una determinada interpretación legal contraria a la Constitución? ¿Es posible concebir que del Art. $93 \mathrm{~N}^{\circ} 6^{\circ}$ de la Carta Fundamental se instaura un amparo judicial como existe en otras latitudes? El paso lógico parece muy grande y vacío de argumentación en la misma sentencia. Por otra parte, los "conflictos de intensidad constitucional" -doctrina que afortunadamente no ha sido reiterada en la jurisprudencia posterior- definen como conflicto de constitucionalidad toda controversia en que se verifique "una cierta intensidad de vínculo" entre el precepto constitucional y su aplicación por el legislador, como también, cuando el propio juez constitucional ha intervenido fijando el sentido y alcance de una norma ${ }^{58}$. De nuevo, la sentencia no explicita cómo este criterio normativo se cimienta en alguna de las normas jurídicas que habilitan al Tribunal para ejercer su competencia. Eso inmediatamente genera una sospecha -factible de corroborar en el

\footnotetext{
${ }^{57}$ Cfr. STC roles $\mathrm{N}^{\mathrm{o}} 2246$, cc. $6^{\circ}$ y $7^{\circ}$ y $\mathrm{N}^{\mathrm{o}} 2379$, cc. $6^{\circ}$ y $7^{\circ}$.

${ }^{58}$ Cfr. STC roles $\mathrm{N}^{\circ} 2437$, c. $7^{\circ}$ y $\mathrm{N}^{\circ} 2363$, c. $4^{\circ}$, voto por acoger.
} 
análisis argumentativo de la sentencia-acerca de una posible usurpación de potestades, sino del juez del fondo, al menos de algún otro órgano.

En síntesis, ambos tipos de límites -institucionales y funcionales-operan como una herramienta de control del ejercicio de jurisdicción que realiza el Tribunal Constitucional, y juntos conforman la garantía institucional de la jurisdicción constitucional y de la jurisdicción ordinaria en sede de inaplicabilidad.

\section{Conclusión}

La garantía institucional de la jurisdicción constitucional y la jurisdicción ordinaria se configura en la práctica por dos tipos de límites: los límites institucionales y los límites funcionales. Cuando se produce una coincidencia entre ambos límites (coincidencia entre las atribuciones que entrega la normativa vigente y la comprensión que el órgano tiene de esas atribuciones) no hay transgresión a la competencia de decisión del otro órgano o, a su vez, no hay una autotransgresión a la propia competencia y función del Tribunal Constitucional.

El conocimiento de los límites institucionales y funcionales de la jurisdicción constitucional permite ejercer un control sobre los principios normativos que nacen de la hermenéutica que hace el Tribunal de aquellos límites. Esos principios son los que van definiendo, caso a caso, aquellas materias que se encuentran bajo la esfera de atribuciones del juez del fondo -conflictos de legalidad-y aquellas que corresponde conocer y resolver al Tribunal Constitucional -conflictos de constitucionalidad-.

\section{BIBLIOGRAFÍA}

Bordalí Salamanca, Andrés, "Organización judicial en el derecho chileno: un poder fragmentado", en Revista Chilena de Derecho, Vol. 36 N² 2, 2009, pp. 215-244.

BRAGE, J., "Estudio introductorio", en Brage. J. (trad.), Estudios sobre la jurisdicción constitucional (Con especial referencia al Tribunal Constitucional alemán), Editorial Porrúa, México, 2011, pp. 1-62.

Brewer-Carías, Allan, La justicia constitucional: procesos y procedimientos constitucionales, Editorial Porrúa, México, 2007.

Bulnes, Luz, "Efectos de las sentencias de la jurisdicción constitucional en la judicatura ordinaria", en Estudios Constitucionales 3/1, 2005, pp. 55-65.

CEA, José Luis, "El proyecto de reforma constitucional sobre los efectos de las sentencias del Tribunal Constitucional sobre la justicia ordinaria”, en Estudios Constitucionales 3/1, 2005, pp. 67-72.

Colombo Campbell, Juan, El debido proceso constitucional, Editorial Porrúa, México, 2007.

Colombo Campbell, Juan, "Los tribunales constitucionales: entre la judicialización de la política y la politización de la justicia constitucional”, en La Ley Fundamental alemana y la Constitución Politica chilena. Estudio constitucional comparado, Editorial Jurídica de Chile, Santiago, pp. 99-117. 
García Martínez, María Asunción, El control de constitucionalidad de las leyes. Recurso y cuestión de inconstitucionalidad, Jurista Editores, Lima, 2005.

Gómez Bernales, Gastón, Las sentencias del Tribunal Constitucional y sus efectos sobre la jurisdicción común, Ediciones Universidad Diego Portales, Santiago, 2013.

Herrera, Alfonso, "El recurso de amparo en el modelo kelseniano de control de constitucionalidad de las leyes ¿un elemento atípico?”, en Bazán, V. (coord.), Derecho Procesal Constitucional Americano y Europeo Tomo II, Abeledo Perrot, Argentina, 2010, pp. 953-972.

Hesse, Konrad, Escritos de Derecho Constitucional, Fundación Coloquio Jurídico Europeo y Centro de Estudios Políticos y Constitucionales, Madrid, 2011.

Hesse, Konrad, "La función jurisprudencial y el Tribunal Constitucional en la Ley Fundamental de Bonn”, en Brage Camazano, Joaquín (trad.), Estudios sobre la jurisdicción constitucional (Con especial referencia al Tribunal Constitucional alemán), Editorial Porrúa, México, 2011, pp. 63-89.

Marshall Barberán, Pablo, "El efecto horizontal de los derechos y la competencia del juez para aplicar la Constitución”, en Estudios Constitucionales, Año 8, No 1, 2010, pp. 43-78.

Morales Tobar, Marco, "Las relaciones entre Poder Judicial y Tribunal Constitucional a propósito del control represivo de inconstitucionalidad de preceptos legales en Ecuador y los efectos de las sentencias", en Estudios Constitucionales, Año 3 No 1, 2005, pp. 173-198.

Navarro Beltrán, Enrique, "Acción de inaplicabilidad por inconstitucionalidad. Notas sobre su evolución histórica en Chile”, en Actualidad Jurídica, v. XI Nº 22, 2010, pp. 21-54.

Navarro Beltrán, Enrique, "Criterios del Tribunal Constitucional en materia de admisibilidad de la acción de inaplicabilidad por inconstitucionalidad de las leyes", en XXXVII Jornadas de Derecho Público, 2007, pp. 189-198.

NúÑez Poblete, Manuel, "Se acata pero no se cumple. Los efectos de la inaplicabilidad en el caso por no pago del bono por desempeño institucional: Gómez Montoya con Corporación Administrativa del Poder Judicial”, en Fermandois, A. (edit.), Sentencias Destacadas 2011, Instituto Libertad y Desarrollo, 2011, pp. 153-171.

NúÑez Poblete, Manuel, "Desaplicación e inaplicación jurisdiccional de las leyes en Chile: Ejercicio de la jurisdicción y control concreto de constitucionalidad", en Revista de Derecho de la Universidad Católica del Norte, Año 19, N 2, 2012, pp. 191-236.

PeÑA, M., "Admisibilidad de requerimientos de inaplicabilidad: Jurisprudencia del Tribunal Constitucional chileno”, en Bazán. V. (coord.), Reflexiones acerca del Tribunal Constitucional y sus competencias a ocho años de la reforma de 2005, Librotecnia, Santiago, 2010, pp. 1037-1054.

PiCa Flores, Rodrigo, "Algunos nudos procesales del control de inaplicabilidad por inconstitucionalidad en la ley orgánica constitucional del Tribunal Constitucional”, en Nogueira, H., (coord.), Reflexiones acerca del Tribunal Constitucional y sus competencias a ocho años de la reforma de 2005, Librotecnia, Santiago, 2013, pp. 9-46.

REsÉNDIZ, Cuauhtémoc, "Relación entre la Jurisdicción Constitucional y la Jurisdicción Ordinaria", en Ferrer, E. (edit.), Décimo aniversario de la Reestructuración de la Suprema Corte de Justicia de la Nación, Suprema Corte de Justicia de la Nación, México, 2005, pp. 193-210.

Rubio Llorente, Francisco, "Sobre la relación entre Tribunal Constitucional y Poder Judicial en el ejercicio de la jurisdicción constitucional”, en Revista Española de Derecho Constitucional, Año 2, 1982. No 4, pp. 35-68.

ZÚÑIGA, Francisco, "Acción de inaplicabilidad por inconstitucionalidad: requerimiento de jueces entre legalidad y constitucionalidad", en Revista de Derecho Público, No 72, 2010, pp. 294-339.

ZÚÑIGa, Francisco, "La acción de inaplicabilidad por inconstitucionalidad en Chile", en Bazán, Víctor (coord.), Derecho Procesal Constitucional Americano y Europeo Tomo II, Abeledo Perrot, Argentina, 2010, pp. 1055-1090. 